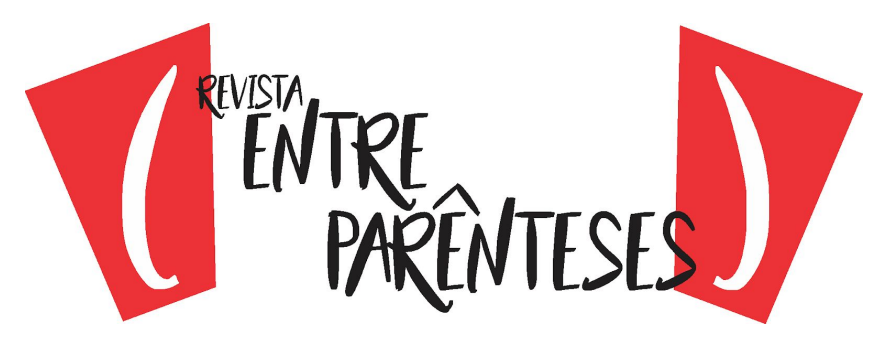

\title{
RAP: INSTRUMENTO DE LIBERTAÇÃO E RECONHECIMENTO DA IDENTIDADE NEGRA
}

\author{
Elaine de Souza Pinto Rodrigues ${ }^{1}$ \\ Universidade Vale do Rio Verde- FCTC/PMTC \\ (elainepacto@yahoo.com) \\ Joseli Aparecida Fernandes ${ }^{2}$ \\ Universidade Vale do Rio Verde - FCTC/PMTC \\ (josyfernanddes@hotmail.com)
}

\begin{abstract}
Resumo: O presente artigo pretende discutir como dialogam o rap e a identidade negra identificando continuidades e rupturas nas relações entre raça, racismo, classe e cultura no discurso e na narrativa musical das letras do rapper Flávio Renegado. Para tanto, iremos apresentar as canções "Black Star" e "Zica", presentes nos álbuns Outono Selvagem e Minha tribo é o mundo, refletindo sobre o padrão estético eurocêntrico da mídia brasileira e questionar a tão falaciosa democracia racial. $O$ fato de a sociedade brasileira buscar o padrão de beleza branco e insistir na ideia de harmonia racial, ao mesmo tempo em que expõe o negro à inferioridade, evidenciou aos afrodescendentes a necessidade de um enfretamento coletivo do problema, em busca do reconhecimento e do autopoder racial em todos os setores. Assim o hip hop apresenta como caraterística bem marcada a questão da negritude, principalmente no rap, entendida como resgate da valorização e reconhecimento da identidade negra. O rapper coloca nos versos a importância da participação dos afrodescendentes na divulgação do movimento, visto que este nasce dessa população, além de denunciar o racismo e falta de representatividade do negro na sociedade.
\end{abstract}

Palavras-chave: rap; identidade negra; enfrentamento; negritude.

\begin{abstract}
This article aims to discuss how rap and black identity interact with each other, identifying continuities and ruptures in the relationships between race, racism, class and culture in the discourse and musical narrative of rapper Flávio Renegado 's lyrics. To do so, we will present the songs "Black Star" and "Zica", present in the albums Outono Selvagem and Minha tribo é o mundo, reflecting on the aesthetic Eurocentric aesthetic of the Brazilian media and questioning the so fallacious racial democracy. The fact that Brazilian society pursues the pattern of white beauty and insists on the idea of racial harmony, while exposing the Negro to inferiority, has shown to Afro-descendants the need for a collective confrontation of the problem in search of recognition and self-power in all sectors. Thus,
\end{abstract}

1 Mestra em Letras pela Universidade Vale do Rio Verde. Este artigo é um recorte da pesquisa realizada para minha dissertação de mestrado, "Não tem como segurar essa ventania": Afirmação da identidade negra em Filhas do Vento, de Joel Zito Araújo, orientada pela Profa. Dra Terezinha Richartz, associada á linha de pesquisa Literatura, história e cultura e ao Grupo de Pesquisa Minas Gerais. Este trabalho deriva de pesquisas desenvolvidas com apoio da Fundação Tricordiana de Educação e da Prefeitura Municipal de Três Corações, por meio de concessão de bolsas.

${ }^{2}$ Mestra em Letras pela Universidade Vale do Rio Verde. Este artigo é um recorte da pesquisa realizada para minha dissertação de mestrado, "Através do meu canto o morro tem voz": o discurso de resistência no rap de Flávio Renegado, orientada pela Profa. Dra. Cilene Pereira, associada à linha de pesquisa Literatura, história e cultura e ao Grupo de Pesquisa Minas Gerais - Diálogos. Este trabalho deriva de pesquisas desenvolvidas com apoio da Fundação Tricordiana de Educação e da Prefeitura Municipal de Três Corações, por meio de concessão de bolsas. 


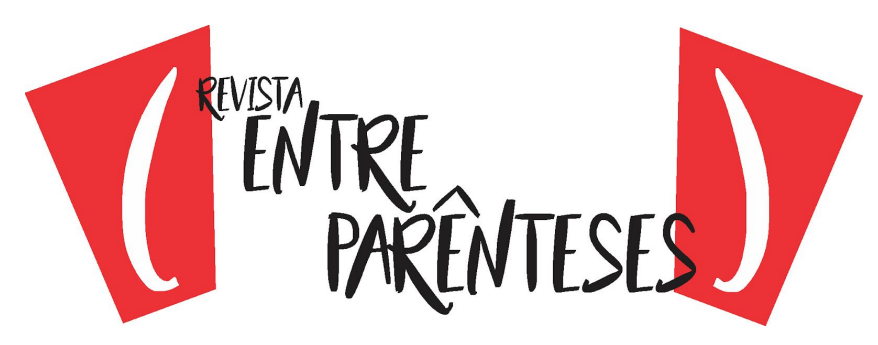

hip hop presents as a very marked characteristic the issue of blackness, especially in rap, understood as a rescue of the valorization and recognition of black identity. The rapper puts in the verses the importance of the participation of people of African descent in the dissemination of the movement, since it is born of this population, as well as denounce the racism and lack of representation of the black in society

Keywords: rap music; black identity; coping; blackness.

Resumen: El presente artículo pretende discutir cómo dialogan el rap y la identidad negra identificando continuidades y rupturas en las relaciones entre raza, racismo, clase y cultura en el discurso y en la narrativa musical de las letras del rapero Flávio Renegado. Para ello, vamos a presentar las canciones "Black Star" y "Zica", presentes en los álbumes Outono Selvagem e Minha tribo é o mundo, reflexionando sobre el patrón estético eurocéntrico de los medios brasileños y cuestionando la tan falsa democracia racial. El hecho de que la sociedad brasileña busque el patrón de belleza blanco e insiste en la idea de armonía racial, al mismo tiempo que expone el negro a la inferioridad, evidenció a los afrodescendientes la necesidad de un enfrentamiento colectivo del problema, en busca del reconocimiento y del autopoder racial en todos los sectores. Así el hip hop presenta como característica bien marcada la cuestión de la negritud, principalmente en el rap, entendida como rescate de la valorización y reconocimiento de la identidad negra. El rapper coloca en los versos la importancia de la participación de los afrodescendientes en la divulgación del movimiento, visto que éste nace de esa población, además de denunciar el racismo y falta de representatividad del negro en la sociedad

Palabras clave: rap; identidad negra; afrontamiento; negritud.

\section{INTRODUÇÃO}

O Brasil durante mais de trezentos anos foi marcado por uma sociedade que condenava o negro à condição de escravizado, o que influenciou o coletivo e deturpou tanto a autoidentidade quanto a identidade atribuída ao negro brasileiro até os dias atuais. Essa opressão e dominação racial geraram revoltas e lutas políticas que atravessaram os séculos passados e permanecem ainda no século XXI quando se pautam pelo resgate de dívidas históricas relacionadas à igualdade social, cultural e econômica entre brancos e negros.

Ao falar em etnia e identidade negra no Brasil, tomamos por pressuposto o multiculturalismo, assim como a existência de diversas identidades nacionais, uma vez que estas "não são coisas com as quais nós nascemos, mas são formadas e transformadas no interior da representação" (HALL, 2006, p. 48). Além disso, nos envolvemos em um embate que desestrutura conceitos estabelecidos socialmente e faz emergir uma discussão necessária e urgente sobre o desenvolvimento da representatividade e da identidade afro-brasileira, suas relações gerais e singulares 


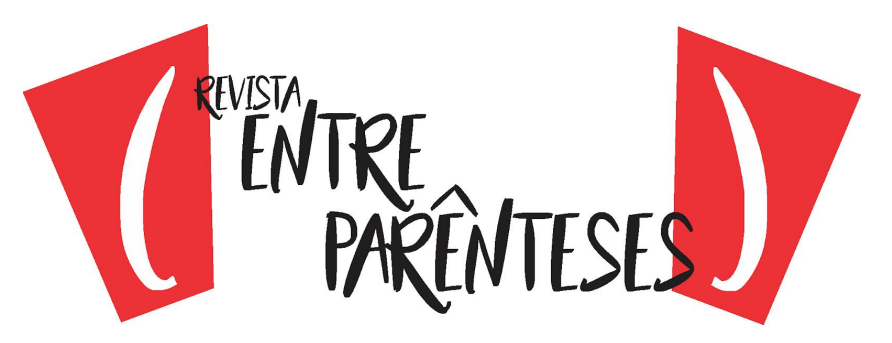

e o enfrentamento das recusas e discriminações que marcam uma sociedade preconceituosa, que se mascara sob a ideia de democracia racial.

Uma forma significativa dessa representatividade é o hip hop, que foi concebido por meio de ações culturais, artísticas e políticas, constituindo-se numa forma de resistência ao possibilitar a manifestação da voz do subalterno, do negro, do marginalizado e de sua reflexão sobre aquilo que aflige e reprime as classes menos favorecidas, associado ainda à diversão e ao entretenimento.

Foi no escopo dessas questões que se delineou este artigo, que tem como objetivo discutir a identidade negra a partir do rap de Flávio Renegado, identificando as maneiras pelas quais sua narrativa musical, a partir das relações sociais e históricas que conformaram nosso país, apresenta o lugar e o status do negro na sociedade brasileira, assim como coloca esse lugar em discussão.

\section{IDENTIDADE NEGRA}

Ao falar em identidade na contemporaneidade, já encontramos uma dificuldade em definir ou delimitar representações sociais e culturais. Atualmente, enfrentamos uma desestabilização do mundo social, surgindo um indivíduo que não se apoia mais exclusivamente em referências tradicionais - pois estas não suprem mais suas exigências e necessidades - e que busca uma mudança urgente nos processos e estruturas sociais e culturais.

Não possuímos, portanto, uma identidade singular, completa, segura e coerente: a identidade está sempre se deslocando e confrontando com uma multiplicidade desconcertante e cambiante de identidades, possibilitando que nos identifiquemos com várias destas, ainda que temporariamente. (Cf. HALL, 2006, p. 13).

Em um cenário conflituoso e permeado por lutas ideológicas, sociais e políticas, pode-se dizer que o século $X X I$, refletindo uma realidade que veio se conformando desde meados do século $X X$, está amplamente atravessado por 


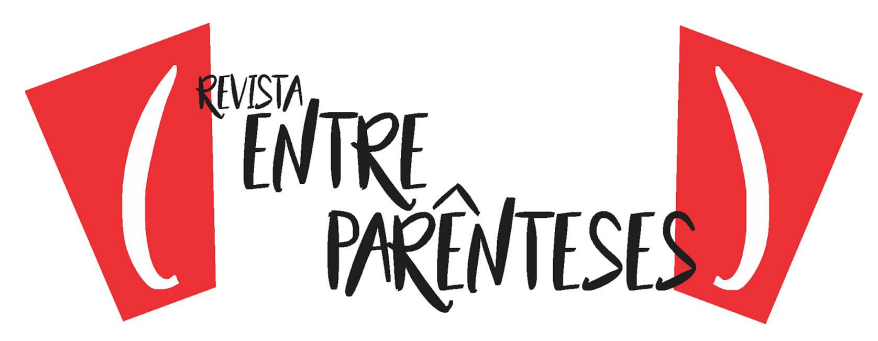

identidades descentradas, fragmentadas, deslocadas e em constante confronto com um referencial estável construído e perpetuado por relações de dominação e opressão, em que se colocam em pauta diversos processos sociais, como observa o sociólogo e culturalista Stuart Hall:

O sujeito previamente vivido como tendo uma identidade unificada e estável, está se tornando fragmentado; composto não de uma única, mas de várias identidades, algumas vezes contraditórias ou não-resolvidas. Correspondentemente, as identidades, que compunham as paisagens sociais "lá fora" e que asseguravam nossa conformidade subjetiva com as "necessidades" objetivas da cultura, estão entrando em colapso, como resultado de mudanças estruturais e institucionais. O próprio processo de identificação, através do qual nos projetamos em nossas identidades culturais, tornou-se mais provisório, variável e problemático. (HALL, 2006, p. 12, aspas do autor).

A fixidez de referências e condutas é substituída, portanto, por uma diversidade de representações e significações sociais e culturais que permite que 0 indivíduo se transforme e se identifique na complexidade das relações de representação que o circundam, as quais são construídas historicamente dentro de uma sociedade globalizada e multicultural. Isso torna a definição de identidade algo extremamente complicado e complexo para as ciências sociais, como afirma Hall:

O próprio conceito com o qual estamos lidando, "identidade", é demasiadamente complexo, muito pouco desenvolvido e muito pouco compreendido na ciência social contemporânea para ser definitivamente posto à prova. (HALL, 2006, p.8, aspas do autor).

Nesta perspectiva, falar sobre identidade é questionar a história e confrontar as relações de poder que estão emaranhadas na sociedade contemporânea, é construir o seu interior a partir de organizações e estruturas exteriores, que são internalizadas por nós e nos fazem agentes de nossa própria história, em uma sociedade marcada pela globalização e pela abertura de fronteiras sociais, culturais e políticas. Isso remete o indivíduo a uma gama vasta e ampla de 


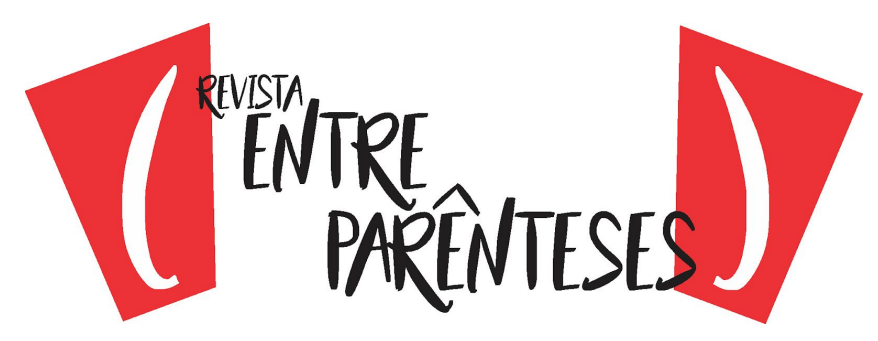

conhecimentos e possibilidades culturais, que ao mesmo tempo que unificam o homem e a cultura mundial, fragmentam-no em várias identidades, provisórias, cambiantes e problemáticas. A identidade passa a ser, na expressão de Hall, uma “celebração móvel”. (HALL, 2006, p.13).

Esse processo que ocorre nas sociedades contemporâneas graças ao fenômeno social da globalização ${ }^{3}$ caracteriza a sociedade como mutante, dinâmica e móvel, revelando o impacto que uma cultura tem sobre a outra, a ruptura que o indivíduo tem com o local para se integrar ao global, descentralizando o poder cultural estabelecido e possibilitando tanto o surgimento de novas identidades quanto o hibridismo cultural das nações. É também nesta perspectiva que o antropólogo argentino Néstor García Canclini aponta "a cultura como instância em que cada grupo organiza sua identidade" (CANCLINI, 2009, p. 43), ou seja, a cultura reafirma e renova as identidades nas sociedades, ultrapassando os sistemas simbólicos de uma só raça ou nação, em circuitos globais, superando fronteiras e permitindo aos diversos grupos abastecerem-se de repertórios culturais diferentes. (Cf. CANCLINI, 2009, p. 43).

Assim, o global passa a ter função norteadora na construção das identidades, pois não há como discutir o sistema de referência que nos determina em um espaço e tempo sem a discussão do global, que estabelece um espaço de múltiplas culturas, ideologias e relações comunicativas.

Consequentemente, todas estas mudanças estruturais e sociais nos permitem uma análise ampla e diversa acerca das identidades pessoais, as quais não são desconsideradas nesse processo. Autores como Anthony Giddens e Pierre Bourdieu definem a identidade como pessoal e social, analisando-a como "representação de si"4 e "conceito de si" , ou seja, como atributos pessoais que irão

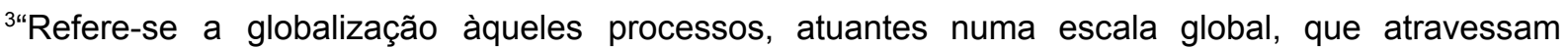
fronteiras nacionais, integrando e conectando comunidades de espaço-tempo, tornando o mundo, em realidade e em experiência, mais interconectado." (MCGREW apud HALL, 2006, p.67).

${ }^{4}$ Pierre Bourdieu afirma que a identidade é a "representação de si" dentro de uma proposta relacional: "ser percebido que existe fundamentalmente pelo reconhecimento dos outros" (BOURDIEU, 2007b, p. 117).
} 


\section{("Wing}

marcar e assinalar o pertencimento a um grupo ou a categorias. Tal análise é essencial para compreendermos as diferenças sociais e a corresponsabilidade do indivíduo na manutenção ou enfrentamento da dominação ideológica, assim como suas consequências na representatividade do grupo ou categoria. Ou seja, para os estudos das minorias, a análise da identidade pessoal é essencial, pois ela marca características de pertencimento ao mesmo tempo em que implica na análise social e coletiva das características de reprodução ou enfrentamento dos referenciais culturais.

Assim, tanto a identidade compreendida como cultural, ou seja, atribuída a um indivíduo ou grupo por pertencer a uma cultura específica, ou a pessoal, "reflexividade da modernidade que se estende ao núcleo do eu" (GIDDENS, 2002, p.37), são discussões relevantes na busca da compreensão do termo identidade e de seu impacto social, pois o subjetivo e o coletivo se entrelaçam e se tornam inseparáveis, uma vez que não há como se vivenciar uma identidade cultural sem a essência do pessoal, e vice-versa.

Nessa perspectiva, numa época em que a integração não é mais apenas regional e nacional, mas ultrapassa tais fronteiras, tornando-se global, discutir sobre identidade negra torna-se um problema complexo, pois não se sustenta mais um nacionalismo étnico, pautado na pureza racial: dentro de uma mesma nação, há minorias que se identificam com culturas diferentes. Então, o que significa ser negro em um mundo imediatista e pautado na intensidade das confrontações culturais globais?

A resposta é multifacetada e flutuante, como a própria identidade, porque somos seres deslocados, fragmentados, atravessados por relações de poder e

\footnotetext{
${ }^{5}$ Anthony Giddens afirma que a identidade é o "conceito de si" a partir da perspectiva da identidade pessoal,explorando a ideia de que "pessoal é político", referindo-se "a questões políticas que fluem a partir dos processos de auto-realização (sic) em contextos pós-tradicionais, onde influências globalizantes penetram profundamente no projeto reflexivo do eu e, inversamente, onde os processos de auto-realização (sic) influenciam as estratégias globais". (GIDDENS, 2002, p. 197).
} 


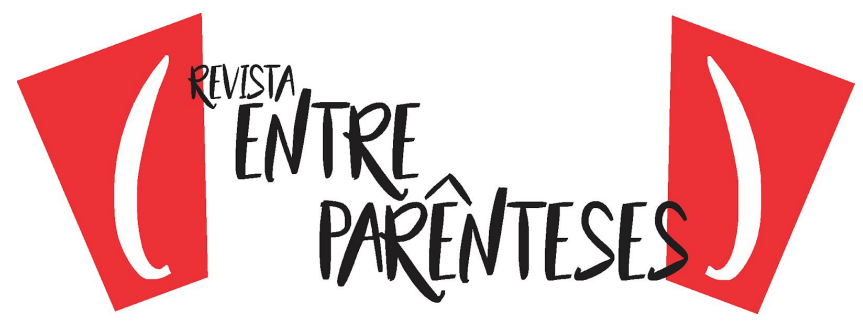

ideologias que nos levam sempre a fazer escolhas e a buscar conhecer, identificar, desculpar, perdoar, reconstruir e perceber as diferenças, ressaltando-as no processo de identificação no interior das representações, para que fiquem mais claras e sejam aceitas no universo sociocultural. Não é possível, portanto, que a identidade negra possa ser vista como plena, única, coerente, uma vez que ela é atravessada por contextos socioculturais, políticos, históricos e educacionais diversos, assim como pelo grau de consciência de cada sujeito, o qual pode ser desigual e mesmo confrontante.

Nesse sentido, conforme explica Kabengele Munanga, antropólogo congolês radicado no Brasil, a consciência histórica tem um papel relevante na formação da identidade negra, principalmente no que se refere ao resgate da autoestima e do respeito, pois a exploração dos negros foi, desde o início, pautada na exploração econômica e apoiada em sua suposta inferioridade em relação ao desenvolvimento técnico, incluída aí a tecnologia de guerra, justificada pelas condições ecológicas, socioeconômicas e históricas da África - e não por aspectos biológicos, como alguns tentaram comprovar. Tais relações de exploração se estenderam ao plano social, fazendo com que se perpetuasse 0 binômio senhor-escravizados. (Cf. MUNANGA, 2006, p. 23).

As representações construídas sobre o negro estão, quase sempre, relacionadas à colonização e à mão de obra escravizada, além de remeterem ao ideal de hegemonia do branco em relação ao negro. Esta classificação epidérmica dos indivíduos resultou em experiências violentas e historicamente construídas no decorrer dos séculos, não apenas no Brasil, mas em vários outros lugares do mundo. Com isso, o negro erigiu, de forma geral, tanto uma identidade pessoal, autoatribuída, quanto uma identidade socialmente atribuída a ele pelos outros, pautada na desvalorização e na depreciação, as quais se apresentam ligadas à cor da pele, às crenças, à relação com o trabalho, com o lazer, com os valores estéticos e, ainda, à sua vitalidade sociocultural. 


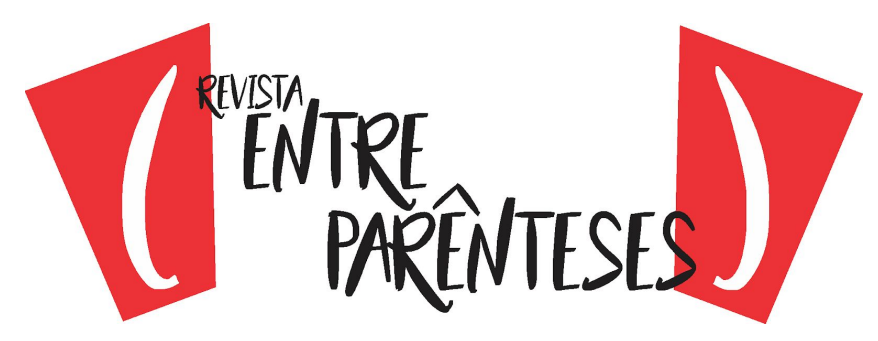

Ao observarmos o povo brasileiro, podemos perceber a presença dos negros africanos em nossa mestiçagem, em nossa silhueta alongada, em nossos cabelos crespos, em nossos gestos macios e andar requebrado (Cf. SOUZA, 2014, p. 7). Mas não podemos negar também um passado de dor e misérias em que os homens brancos escravizavam homens negros pelo simples fato de se sentirem superiores, por terem dinheiro para comprar outros homens, retirando-lhes o direito de serem cidadãos completos na sociedade em que estavam inseridos, impedindo seu trânsito espontâneo, obrigando-os a serem totalmente submissos e oprimidos por castigos e violências.

Assim, o Brasil, após a abolição, se apoiou numa ideologia em que a condição do ex-escravo, do afrodescendente e do mestiço era mascarada e se deixava encobrir pela política da democracia racial, segundo Florestan Fernandes, "com o padrão correspondente de dominação racial tradicionalista". Isso significava, na verdade, a resistência à aceitação da igualdade de condição, pelo branco, com o negro e com o mulato. (FERNANDES, 1965, p. 78). Tal ideologia teria construído no Brasil "o preconceito de cor", assim descrito por Fernandes:

O "preconceito de cor" elaborava-se como categoria histórico-social, indicando porque "classe" e "raça" se misturavam de maneira tão intricada. Dois tipos de barreiras se entrecruzariam (sic), de modo imperceptível ou dissimulado aos olhos do "branco", complicando o peneiramento social do "negro" e pervertendo a normalidade da ordem social competitiva e democrática, mais ou menos fechada para os "homens de cor". (FERNANDES, 1965, p. 78, aspas do autor).

Os negros no Brasil, portanto, sempre enfrentaram o racismo e a desigualdade social, pois mesmo após a abolição da escravatura eles continuaram sofrendo discriminação, manifestada pelas dificuldades de se integrarem no contexto intelectual, econômico e social, o que Ihes conferiu as imagens de impotentes, miseráveis e periféricos. (Cf. SILVA, 1987, p. 39). Assim, o que de fato caracteriza a marginalização do negro é o racismo, que procura de todas as formas 


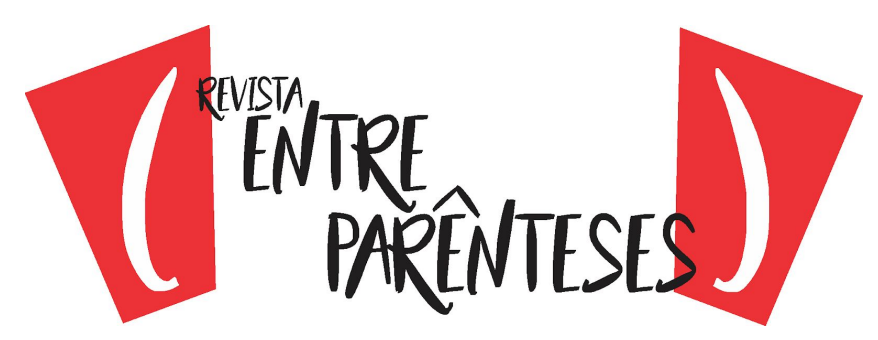

descaracterizar a identidade negra, negando sua história, sua base cultural, sua beleza física e seus desejos, enfim, negando ao negro o direito de ser negro. (Cf. SILVA, 1987, p. 38).

O que resulta dessa nova proposta de convivência social é, de fato, uma maneira mais sutil de continuar o processo de discriminação reinante nesta sociedade capitalista. Mudam-se os "rótulos", mas os conteúdos são os mesmos. Por exemplo: as convocações para novos tipos de emprego [...] "Precisa-se de secretária, com boa aparência..." A partir dessas formas sutis de discriminação, chegamos à manutenção da chamada "democracia racial". Esse foi um dos métodos aplicados sobre a pessoa do negro, procurando mantê-lo à distância de todo o processo de construção da sociedade capitalista. (SILVA, 1987, p. 41, aspas do autor).

Pode-se observar, nessa perspectiva, que o mito da democracia racial resultou no Brasil, desde o período colonial até os dias atuais, em uma supervalorização do branco e em um descrédito total da cultura afro, impedindo tanto a conscientização do negro quanto a construção de uma representação positiva, acabando por interferir até mesmo em sua autoestima.

Tal situação muitas vezes gera problemas de identidade, pois os negros pressionados pela educação eurocêntrica negam sua negritude e investem em recursos estéticos capazes de fazer com que se assemelhem aos brancos, perpetuando o desejo da branquitude como padrão estético e como único horizonte possível para que se busque uma vida mais digna e justa.

A sociedade brasileira, historicamente tem negado o racismo, o que contribuiu para a produção e reprodução de tantas formas de discriminações e preconceitos. A mídia, como um dos principais meios de reprodução de valores, espaços e posições, nesse contexto sempre transmitiu a ideologia da classe dominante, massacrando o negro e obrigando-o a viver como um ser secundário, relegado à marginalidade. Nessa perspectiva, o negro, independentemente de seu desempenho ou talento, é sempre subjugado e fadado a posições inferiores, sendo constantemente alvo de novos estereótipos que são continuamente produzidos, pois 


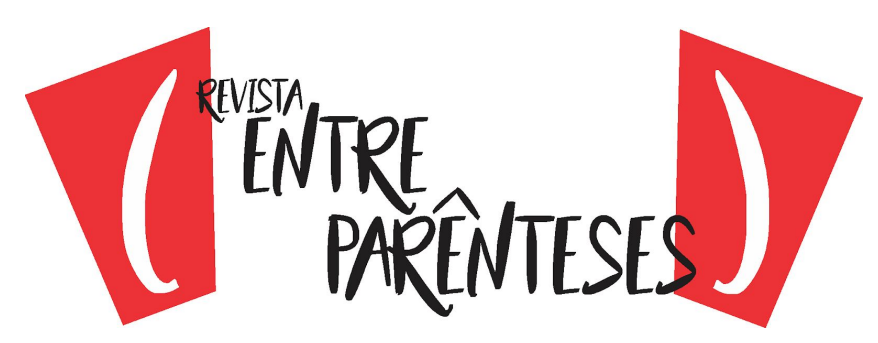

a crítica não se baseia em seu potencial, mas na identificação e nas representações que os brancos fazem a respeito deles.

Assim ao pensarmos sobre resistência e identificação, temos uma expressão artística que dá a voz ao povo negro e se constitui como instrumento de luta e identidade da voz da periferia: o rapper. Nesse sentido, a arte aparece como um instrumento político capaz de sensibilizar as pessoas que com ela têm contato, colocando em evidência o que há de mais terrível na realidade de preconceito racial em que vivemos.

\section{A VOZ DOS RENEGADOS}

Desde o seu surgimento, o hip hop apresenta como característica bem marcada a questão da negritude, temática muito abordada nos quatro elementos que o constituem: rap, grafite, break e MC, principalmente no rap. Muitas das letras do rap fazem menção ao nosso passado, a nossa ancestralidade e a histórias de lutas que envolvem a população negra, através de um discurso que retrata a preocupação do rapper com a questão da desigualdade racial que atrelada à desigualdade de classe transforma o negro num modelo de ser periférico. O rapper coloca nos versos a importância da participação dos afrodescendentes na divulgação do movimento, visto que este nasce dessa população.

José Carlos Gomes da Silva, no trabalho "Arte e Educação: a experiência do Movimento Hip Hop Paulistano", traz uma reflexão sobre os rappers da cidade de São Paulo, a qual podemos remeter aos rappers brasileiros de forma geral. Silva diz que

A partir do "autoconhecimento" sobre a história da diáspora negra e da compreensão da especificidade da questão racial no Brasil, os rappers elaboraram a crítica ao mito da democracia racial. Denunciaram o racismo, a marginalização da população negra e dos seus descendentes. Enquanto denunciavam a condição de excluídos e os fatores ideológicos que legitimavam a segregação dos negros 


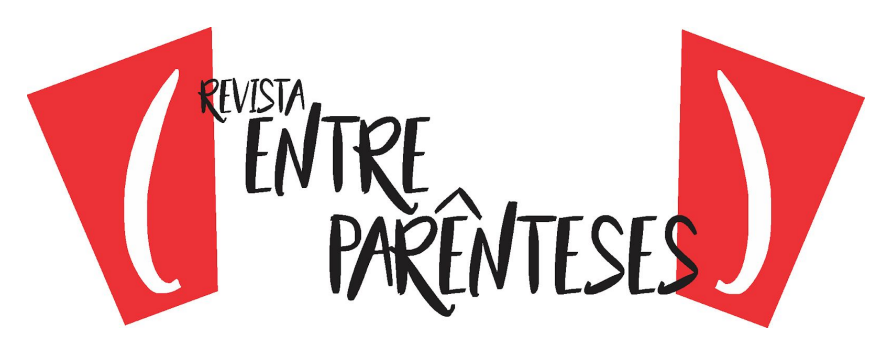

no Brasil, os rappers reelaborara também a identidade negra de forma positiva. A afirmação da negritude e dos símbolos de origem africana e afro-brasileira passaram a estruturar o imaginário juvenil, desconstruindo-se a ideologia do branqueamento, orientada por símbolos do mundo ocidental. [...] A valorização da cultura afro-brasileira surge, então, como elemento central para a reconstrução da negritude. (SILVA, 1999, p. 29-30, aspas do autor)

Flávio de Abreu Lourenço, rapper mineiro de Belo Horizonte, que já produziu três álbuns de 2008 a 2016, nasceu no ano de 1982, foi criado na comunidade Alto Vera Cruz, em Belo Horizonte. Assistiu desde pequeno a luta da mãe para criar sozinha seus três filhos, sendo ele o do meio. Começou sua carreira artística no hip hop aos treze anos e integrou grupos musicais que duraram pouco tempo como o Brothers do Rap. O apelido recebido na infância "Renegado" foi assumido quando entrou para o mundo artístico.

No ano de 1997 criou o grupo Negros da Unidade Consciente, o NUC, em parceria com sua irmã Dani Crizz e com Negro F e DJ Francis. Fizeram shows em vários lugares do Brasil e estiveram à frente de relevantes projetos sociais no Alto Vera Cruz. O grupo era bem eclético e suas músicas transitavam por outros estilos musicais, com letras que apresentavam um significativo apelo social. O grupo teve fim no ano de 2007, quando o rapper assume sua carreira solo a convite da produtora musical Danusa Carvalho.

Em agosto de 2008, Renegado lançou seu primeiro álbum Do Oiapoque a Nova York, com 13 faixas. A partir do reconhecimento desse trabalho e dos diversos shows de divulgação que fez no interior do estado por meio do Projeto Natura, Renegado foi convidado a fazer shows na Europa, Oceania e Américas, encerrando a sua turnê em Nova York, no Central Park.

No ano seguinte, venceu o Hútuz, o maior festival de hip hop da América Latina, nas categorias revelação e melhor site, ficando assim internacionalmente reconhecido. Ainda nesse ano lançou seu primeiro clipe, com a música "Santo Errado", que pertence ao seu primeiro álbum. O álbum Minha tribo é o mundo, é lançado em 2011, trabalho que levou o rapper a percorrer o país e participar de 


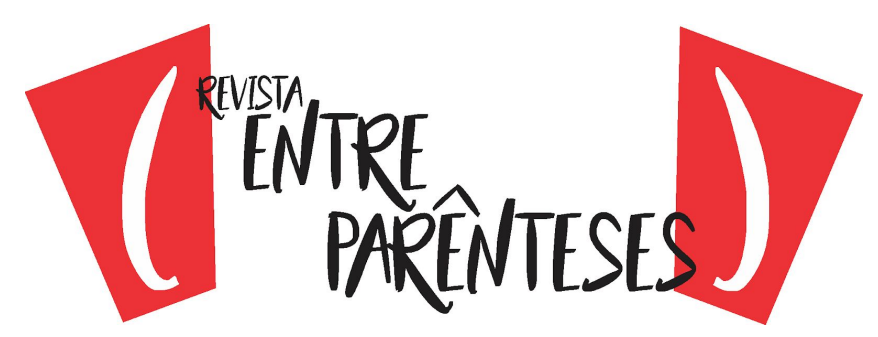

importantes festivais como o Black2Black e o Rock in Rio. Ainda em 2011, Renegado e Danusa Carvalho fundaram a Associação Cultural Arebeldia entidade privada, sem vínculos partidários, religiosos ou lucrativos, que tem como objetivo a promoção da transformação social e a implantação de diversos projetos socioculturais na região do Alto Vera Cruz, como cursos de capacitação para inclusão no mercado de trabalho e projetos artísticos-educacionais diversificados.

No ano de 2016, lançou seu terceiro álbum Outono Selvagem, que agrupava o EP Relatos de um Conflito Particular, lançado em 2015 com sete faixas musicais que traziam como tema os sete pecados capitais e outras sete músicas que compôs logo após o lançamento do EP, estas relacionadas às virtudes relatavam um pouco da sua própria história de vida.

O que podemos observar nas produções de Flávio Renegado é que suas letras abordam as principais dificuldades enfrentadas pelas populações periféricas, representadas pela realidade do Alto Vera Cruz, região em que ele passou toda a sua vida. Além disso, o rapper alude também o tema da exclusão do negro na sociedade de uma forma mais positiva, buscando não ressaltar apenas os aspectos negativos. Ao mesmo tempo em que aponta também revela o lugar de resistência de muitos, valorizando, em canções como "Black Star" e "Zica", por exemplo, a atitude de negros que lutam diariamente para a afirmação da negritude.

$\mathrm{Na}$ letra de "Black star", vemos como o rapper implicitamente coloca em pauta temas como preconceito, racismo, desigualdade social, resistência e enfretamento das dificuldades de quem é preto, pobre e morador de uma favela, aliando isso a uma valorização da cultura negra, ao se rotular, de maneira bem irônica (e, portanto, desmascarando valores ideológicos da classe dominante), como "consumo da filha do patrão".

Querem que a humildade seja a virtude de todo negão Migalhas pro meu povo, a pauta desse jogo presídio e prisão Sou preto rebelado que não aceitou ser chamado de ladrão Hoje Black star, o sonho de consumo da filha do patrão 


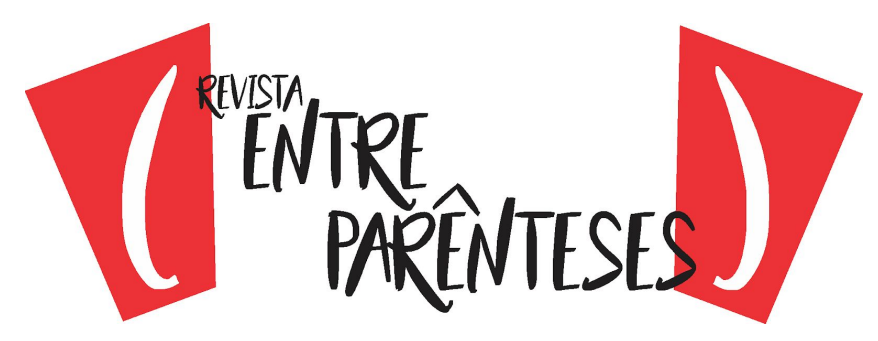

A canção está presente no álbum Outono Selvagem, que constrói uma narrativa a respeito dos sete pecados capitais, que seriam os principais causadores de tanta violência nos tempos atuais. Ao transitar pelo terreno da gula, avareza, luxúria, ira, inveja, preguiça e soberba, o rapper "bota os pensamentos pra fora, reflete, se indigna, protesta" com atitudes de encorajamento que comportam "iniciativa [...], visão de mundo, uma postura ética, um posicionamento que não se rende ao silêncio, à resignação de sofrer de calado" (BERILLO apud CAMARGOS, 2015, p. 86). Vejamos a letra de "Black star":

Pra justiça, chama Xangô

Pra batalha Ogum é o mais forte

Ontem fui caça hoje eu sou caçador

Quem me guia nessa trilhas é Oxossi

Sou pele preta vigiada

As sentinelas estão montadas

Pensão que vão me deter

Não sabem nada

Já venci a fome e a farda

Cara feia dos caretas não me faz tremer

Sobrevivente no Brasil

Puta de país Hostil

Onde é crime preto e pobre ter poder

Meu passado é meu presente

Já arrastei corrente

Mas hoje entrei no game pra vencer

Ecoo, grito forte na senzala

Nego canta, nego dança

Não existe mais chibata

Querem que a humildade seja a virtude de todo negão

Migalhas pro meu povo, a pauta desse jogo presídio e prisão

Sou preto rebelado que não aceitou ser chamado de ladrão

Hoje Black Star, o sonho de consumo da filha do patrão

Pra justiça, chama Xangô

Pra batalha Ogúm é o mais forte 


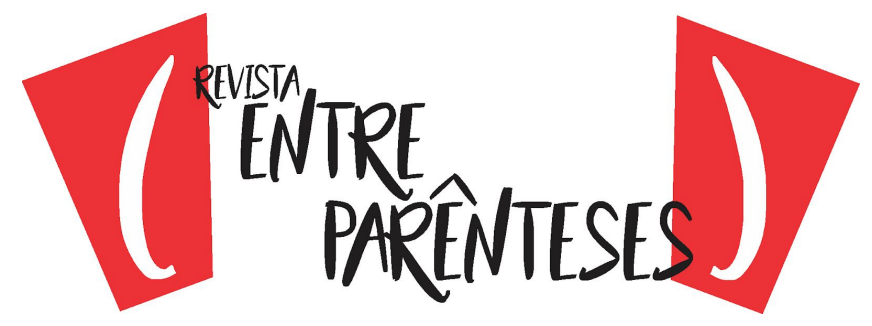

Ontem fui caça hoje eu sou caçador

Quem me guia nessa trilhas é Oxossí

Enquanto nos empurram cachaça e cocaine

Devolvemos para eles Basquiat, Coltrane

Querem nos tirar tudo inclusive your name

Mas pergunta pra esses putos, qual my nickname?

Eu sou Ira! Cores e Dores,

sabores, odores

Minha rima é guerra, inimigos não mando flores

Sou power como James, mais um nigga a sorrir

Flavio Renegado dinastia de Zumbi

Ecoo, grito forte na senzala

Nego canta, nego dança

Não existe mais chibata

O título da canção nos conduz a dois caminhos: seria uma referência à linha de navios a vapor chamada "Black Star", comprada por um dos maiores líderes negros deste século, Marcus Garvey (Cf. CASHMORE, 2000, p. 227-228), expressando mais uma vez a relação dos temas tratados no rap com tudo aquilo que nos remete à história dos negros. Um segundo sentido para a expressão inglesa pode ser dado por sua tradução, já que em língua portuguesa seria "estrela negra". Nas duas acepções, há a referência à figura do negro no sentido de seu empoderamento.

Os primeiros versos que compõem a canção já apontam a descrença do rapper na justiça dos homens. Ao dizer que para justiça e para batalha é melhor apelar para a religiosidade e clamar pela intercessão das entidades sagradas ("Xangô", "Ogum" e "Oxossi"), Renegado sugere que já não acredita na justiça terrena, feita pelos homens. Ao utilizar termos como "Xangô", "Ogum" e "Oxossi" nomes que se referem a Orixás da Umbanda, religião afro-brasileira - o rapper reafirma ainda o seu compromisso com as suas origens, bem como a sua crença e a sua fé, estabelecendo, via os orixás, a relação com sua comunidade.

Pra justiça, chama Xangô 


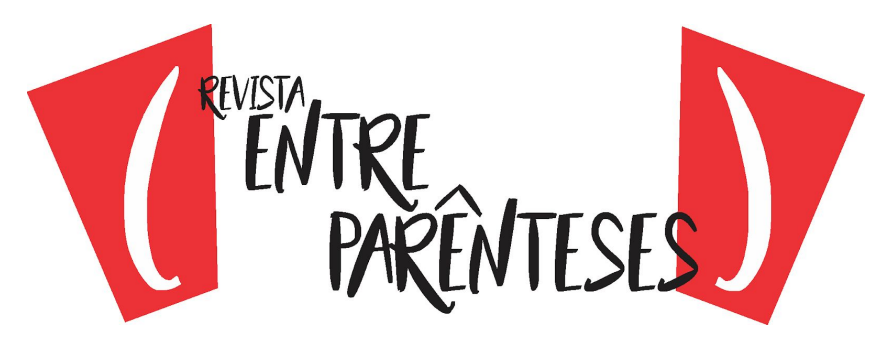

Pra batalha Ogum é o mais forte

Ontem fui caça hoje eu sou caçador

Quem me guia nessas trilhas é Oxossi

O racismo e o preconceito, colocados como tema central da canção, aparecem através de uma série de metáforas e jogos de palavras, numa forma de protestar e fazer as pessoas refletirem sobre como os negros são tratados (no Brasil), corroborando as ideias de Hollanda, quando afirma que o rap enfrenta questões raciais de um modo mais reflexivo (Cf. HOLLANDA, 2012b, p. 27), como podemos observar nos versos a seguir:

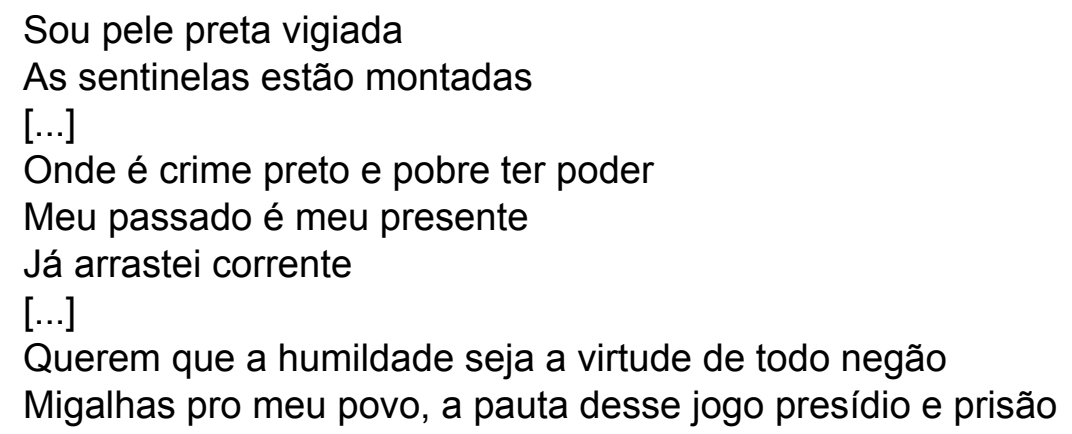

"Black Star" é a canção que trata da questão do racismo e do preconceito que resulta nas mais diversas formas de violência contra o negro, porém retratando alguns negros que conseguiram se sobressair nesse cenário: "Enquanto nos empurram cachaça e cocaine / Devolvemos para eles Basquiat, Coltrane". O verso "Meu passado é meu presente" reafirma a postura de resistência negra e a ancestralidade do rapper, imerso no sentido de pertencimento da comunidade. Se no passado, "já arrastei corrente" e hoje "não existe mais chibata", isso não significa que a violência ao negro deixou de ser praticada. Muito pelo contrário, a ele é ainda reservado um lugar de exclusão e de aprisionamento sociais, conforme vemos na canção. A esse respeito, Tella observa que "em meio a esse conjunto de denúncia e revolta" próprios do rap, "ganha destaque o tema preconceito social e, principalmente, o racial", em que abordam "estigmas construídos pelo imaginário 


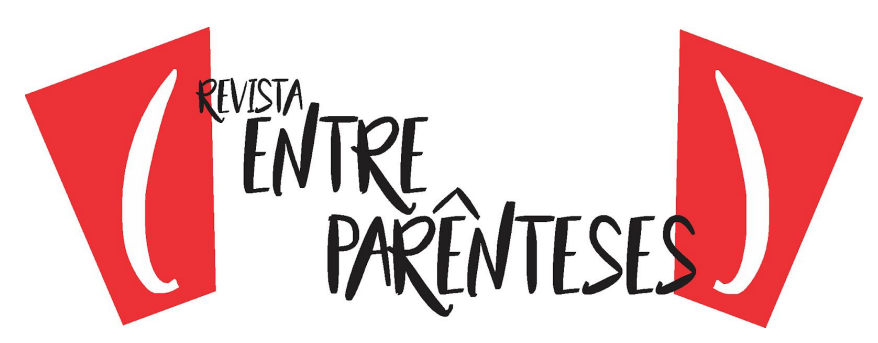

social, no qual as vítimas em potencial são os jovens negros que moram que moram na periferia". (TELLA, 1999, p. 60)

As rimas críticas de Renegado escancaram a história do povo negro e de seu sofrimento, no passado e no presente, evidenciando uma linha de continuidade histórica. Mas em nenhum momento o rapper incentiva para que se reaja de maneira violenta a essa violência histórica e sim através do seu exemplo de vida - de um negro que, apesar de também ter passado por várias provações, conseguiu vencer na vida. Por isso, ele rebate: "Enquanto nos empurram cachaça e cocaine / Devolvemos para eles Basquiat, Coltrane".

Ao relatar que também enfrentou discriminação, Renegado está valorizando sua experiência de vida e a relação desta com sua obra, pois, segundo Silva, "ter passado pelo processo de exclusão relacionado à etnia e à vida na periferia surge como uma condição para a legitimidade artística", "a condição de excluído surge no discurso do rapper como objeto de reflexão e denúncia", é, pois, "a dimensão pessoal que possibilita o desenvolvimento da crônica cotidiana", dando a ele a condição de ser porta-voz "desse universo silenciado em que os dramas pessoais e coletivos desenvolvem-se de forma dramática" (SILVA, 1999, p. 31).

\author{
Pensam que vão me deter \\ Não sabem nada \\ Já venci a fome e a farda \\ Cara feia dos caretas não me faz tremer \\ Sobrevivente no Brasil \\ Puta de país Hostil \\ $[\ldots]$ \\ Meu passado é meu presente \\ Já arrastei corrente \\ Mas hoje entrei no game pra vencer \\ Ecoo, grito forte na senzala \\ Nego canta, nego dança \\ Não existe mais chibata \\ Querem que a humildade seja a virtude de todo negão \\ Migalhas pro meu povo, a pauta desse jogo presídio e prisão
}




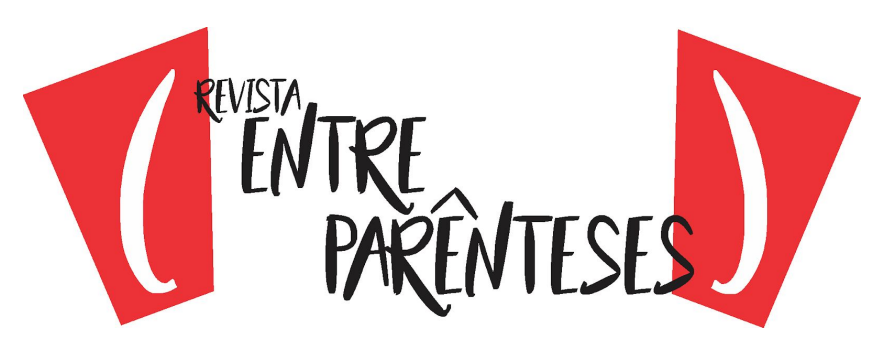

Para Guimarães, o alvo do rap é "a denúncia das desigualdades e a discriminação e, seu universo refere-se a um 'local' que está remetido ao 'global'”, pois "periferia é periferia em qualquer lugar" (GUIMARÃES, 1999, p. 47). Assim, essa condição de exclusão por ser negro não é algo exclusivo do rap mineiro e brasileiro, mas está enraizada na própria construção social do negro no Brasil e em países que escravizaram populações negras africanas. Mas o que distingue o discurso de Renegado de tantos outros rappers é a forma como formata sua canção pela não incitação da violência e pela apologia e crença da/na paz, tendo o rap como compromisso e arma, pois ele é o "preto rebelado que não aceitou ser chamado de ladrão/hoje black star, o sonho de consumo da filha do patrão". Nesse caso, a figura do negro se configura, aqui, como aquele que, apesar de todo o tipo de humilhação e sofrimento a que foi submetido em nosso processo histórico (e que ainda será), pode conseguir ser reconhecido pelos seus talentos.

Outra canção que também trata de todo o processo de discriminação sofrido pela população negra é "Zica", no qual Renegado, utilizando-se de figuras negras de destaque no Brasil, aponta que é possível enfrentar a questão do racismo positivamente, através das diversas formas de arte.

Lázaro Ramos na tela seja cinema, novela Ronaldo Gaúcho marcando de bicicleta (É Zica) Anderson Silva número um no fight É como Renega comandando o MIC (é Zica mesmo)

Nesta canção, a narrativa do rapper é construída a partir das conquistas do povo negro (especialmente do negro brasileiro), bem como da posição social ocupada por estes, cuja ascensão neste país é sempre mais difícil e dolorosa (e não se dá senão por meio da luta). Vejamos a letra:

Eu sou zica mesmo (eu sou)

Eu sou zica mesmo (Nego!)

Na base ou no profi sou titular a artilheiro (REFRÃO)

Entro no campo da vida, chego suando a camisa 


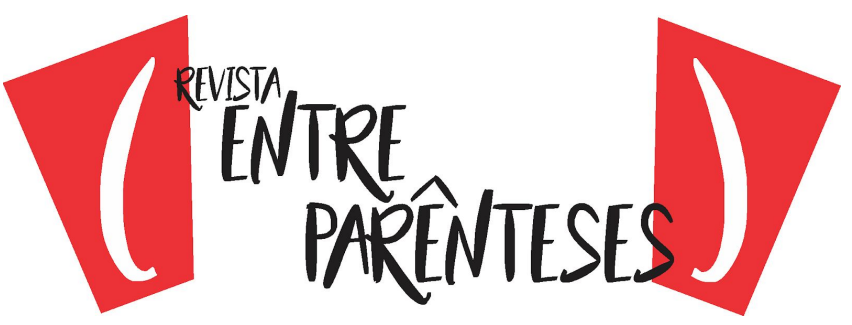

Talento, raça e ginga, problema na boa se dribla Agito geral, deixando a massa quente Zé povinho é que não fica contente

De um bom jogo, nunca tive medo Habilidade, humildade, isso nunca foi segredo Vencendo a pobreza, fazendo do pódio a meta O sucesso meu parceiro, coisa mais que concreta Sou um vencedor, e isso já é fato $E$ de fato, qualquer bola que chega eu mato Pra seleção da vitória eu já fui convocado Vou devolver pro gueto o orgulho que foi roubado

E continuo na missão, doa a quem doer Quem não se corrompeu, só o tempo vai dizer Buxixa difama, fala e fala a esmo Não me abala, não me atinge, porque

[REFRÃO]

Lázaro ramos na tela, seja cinema, novela Ronaldo Gaúcho marcando de bicicleta (É Zica) Anderson Silva número um no fight É como renega comandando o MIC ( é Zica mesmo) Elas mandam demanda, mas minha fé é de bamba Que quebrante quebra com uma oração Mantenho a mente aberta, e o corpo fechado Sempre guiado pelo coração

Responsa de homem, alma de menino que guia o destino com a própria mão

Se a vida é um game, não jogue sozinho de um lado tem Cosme e de outro Damião

Uns dizem que é dom outros dizem que é sorte Uns querem as de cem, Eu quero os malote Ai parceiro vê se entende qual que é o processo

Eu quero menos ordem e bem mais progresso $O$ acesso é touch Screen celular, televisão Mas diz o que você faz com tanta informação Vou te contar um segredo Eu tô na pole position por que

[REFRÃO]

O título "Zica", gíria comumente utilizada (pelos manos) para aludir ao que “dá errado" (Cf. RIGHI, 2011, p. 505), aparece, na canção, para reforçar o lado 


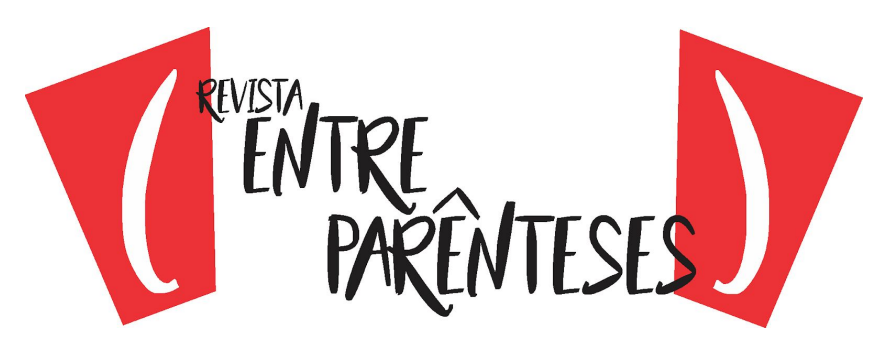

inverso da história negra no país, ao evidenciar os negros que conseguiram driblar o determinismo social, inscrevendo-se em uma história de ascensão. Com o intuito de propagar o seu discurso de resistência e atitude, de modo que possa reverter essa condição de excluído e marginalizado, Renegado tece a narrativa de "Zica" valorizando e destacando o trabalho de alguns desses negros, muitas vezes oprimidos, sem oportunidade de terem seus trabalhos reconhecidos em uma sociedade racista (ainda que se fale de um discurso que negue o racismo).

A música é um dos aspectos que destaca homens negros do Brasil que alcançaram sucesso e publicidade, reforçando mesmo a própria imagem do rapper que, diante de todas as condições a que foi submetido ao longo de sua vida, teria tido motivos para ser um marginal, mas que conseguiu superar as adversidades.

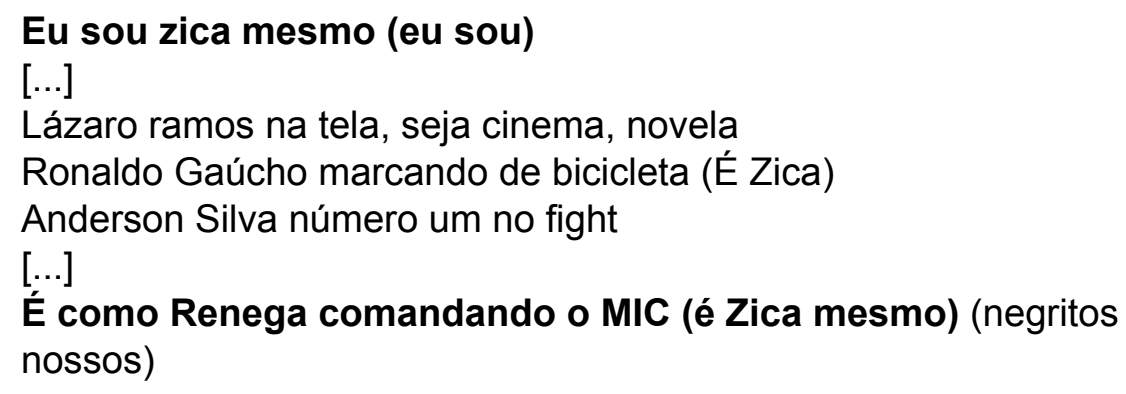

Podemos observar que o rapper fala metaforicamente do jogo da vida como um jogo de futebol, aludindo a este como uma das mais visíveis formas de ascensão social do negro. Ele destaca que, nesse jogo, por mais que se possa contar com a sorte, o que nos faz vencedores é a maneira de como reagimos dentro do jogo, como podemos confirmar nos versos seguintes:

Entro no campo da vida, chego suando a camisa Talento, raça e ginga, problema na boa se dribla $[\ldots]$

De um bom jogo, nunca tive medo Habilidade, humildade, isso nunca foi segredo Vencendo a pobreza, fazendo do pódio a meta O sucesso meu parceiro, coisa mais que concreta Sou um vencedor, e isso já é fato

$\mathrm{E}$ de fato, qualquer bola que chega eu mato 


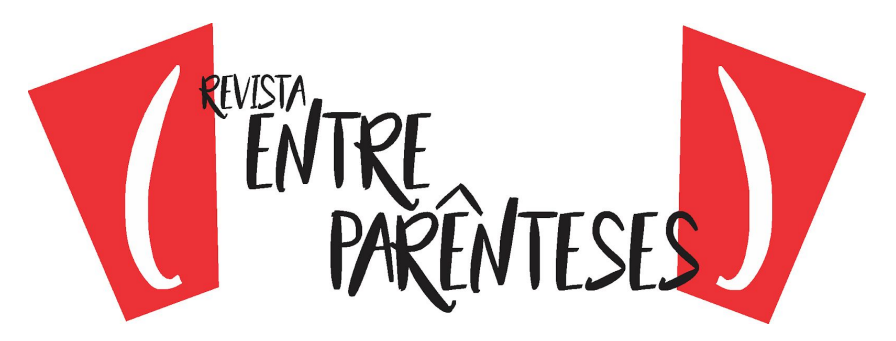

Pra seleção da vitória eu já fui convocado Vou devolver pro gueto o orgulho que foi roubado E continuo na missão, doa a quem doer Quem não se corrompeu, só o tempo vai dizer $[\ldots]$

Se a vida é um game, não jogue sozinho de um lado tem Cosme e de outro Damião

Uns dizem que é dom outros dizem que é sorte Uns querem as de cem, eu quero os malote Eu tô na pole position por que (Porque eu sou Zica)

A canção explora o sentido emblemático do rap: a sua missão de transformação social. Seus versos repletos de palavras que encorajam e incitam uma forma de reagir positivamente e "devolver ao gueto o orgulho que foi roubado" e apesar de suas palavras abrandarem suas reais expectativas, o rapper deixa claro que ele não quer ordem, mas sim evolução. $O$ que ele deseja realmente é que as pessoas sejam mais evoluídas para se livrarem de ideias tão racistas e segregadoras e aceitem que os negros também são merecedores de glórias e dignos de ocupar certas posições.

A ideia expressa na canção pode ser mais bem refletida a partir das considerações do cineasta mineiro e ativista negro Joel Zito Araújo quando este afirma que a branquitude "se tornou o padrão de referência" da sociedade, pois, mesmo inconscientemente, há um forte "desejo do branqueamento na construção de imagens sobre o país" (ARAÚJO, 2006, p.74). O autor discorre sobre as diversas formas de que as minorias raciais são submetidas a todo o tipo de discriminação e exclusão social. No cinema e na telenovela brasileiros, o negro e o mestiço, por exemplo, só ocuparão papéis que revelam "estereótipos negativos", representando personagens como empregados domésticos, favelados, presidiários, escravos, etc. ou outros que não sejam de destaque.

Araújo defende que a ideologia do branqueamento reforça a estereotipia e contribui para a exclusão social de negros e indígenas, enfatizando "um eterno sentimento racial de inferioridade, e uma consciência difusa e contraditória de ser uma casta inferior que deve aceitar os lugares subalternos e intermediários do 


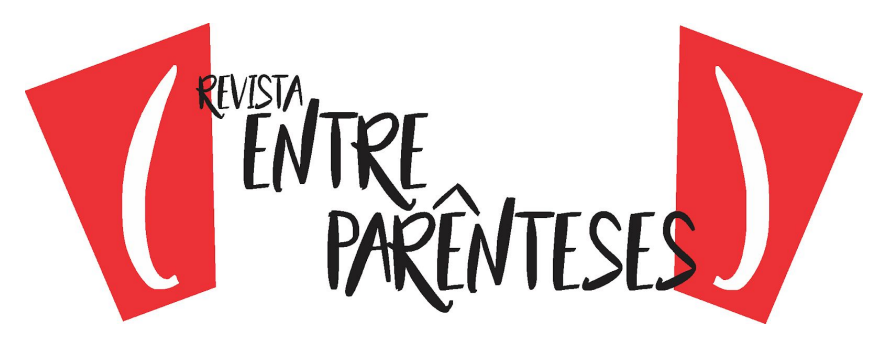

mundo social" (ARAÚJO, 2006, p.77). Enquanto que para Renegado, a "zica" está justamente na inversão da "ideologia do branqueamento" que permeia a sociedade brasileira, pois se esperavam ver nas telas apenas os brancos bonitos, também verão atores negros como Lázaro Ramos, considerado uma estrela da TV, ou ainda jogadores de futebol, como Ronaldo Gaúcho, que conseguem se destacar pelo seu desempenho e não apenas pela sua aparência. Nesse sentido, Araújo observa que

Os nossos jogadores negros-mestiços que na última Copa do Mundo [o cineasta refere-se ao ano de 2004] levaram mais uma vez ao topo a imagem do país, e o orgulho da nossa nacionalidade, são obrigados a suportar a permanente humilhação pelo estigma de suas aparências, sua "impura" feiúra (sic), nas inúmeras comparações e em eleições dos homens mais bonitos da última copa mundial de futebol, que, "naturalmente", escolheram o inglês David Beckham e outros homens brancos. (ARAÚJO, 2006, p.77)

Entretanto, como observado nas canções analisadas neste artigo, é comum o rap se configurar como uma forma de protesto das classes marginalizadas, utilizando esse discurso para criticar a sociedade. Tal crítica resulta da discrepância entre as classes sociais e do preconceito contra a favela e seus moradores. Renegado, porém, ainda que não fuja à regra no que diz respeito ao caráter contestatório e de denúncia social presentes em sua música, destaca em suas composições um discurso mais pacificador, no qual faz suas críticas e denúncias de modo mais ameno e como uma linguagem menos inflamada.

\section{CONSIDERAÇÕES FINAIS}

A rap é a voz da periferia, mais especificamente, das potencialidades e representação da realidade e do povo negro, que ainda sofre com a ideia de um passado de escravizados que influenciam o imaginário coletivo e prejudica a representatividade e o desenvolvimento da identidade negra. 


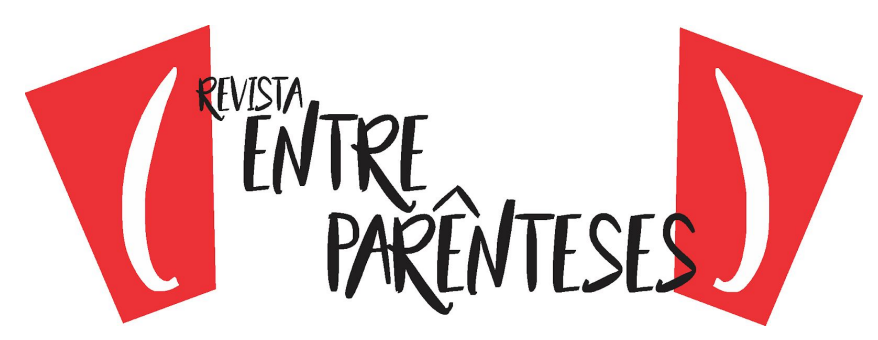

Neste artigo, buscamos a partir das duas canções analisadas do rapper Flávio Renegado, refletir o papel do negro na sociedade envolvendo em uma discussão que coloca a sociedade em xeque. Isso é feito por meio de uma linguagem que não é neutra, mas que manifesta uma crítica social que atinge e sensibiliza a respeito das ideologias e determinismo da história dos negros desde a escravidão.

O rapper Flávio Renegado em suas canções evidencia dois discursos: um, de denúncia e apontamento dos valores da classe dominante que exclui o negro e pobre da favela; outro, de esperança e crédito na ruptura de naturalizações culturais que inferiorizam os negros e os incapacita. Nesta perspectiva, o rap torna-se um instrumento de libertação das amarras de um passado de escravismos e de preconceitos que inferiorizaram e permanece ainda nos dias atuais estereotipando e desvalorizando uma cultura e um povo a partir de submissões de práticas discriminatórias.

Tais reflexões, no entanto, nos permitem perceber a representatividade do negro na sociedade brasileira, a partir das vivências de cidadãos negros que muitas vezes são excluídos ou calados devido a preconceitos e discriminações. Além disso, as canções problematizam o modo como a violência diária ao negro podem levar ao conformismo opressor e à aceitação de estereótipos que perpetuam a negação de seus direitos, impedindo seu desenvolvimento e reconhecimento da negritude.

Flávio Renegado coloca o rap como um instrumento social e propõe uma experiência estética que rompe com o silêncio das vozes periféricas e com a ideia de associação do negro aos estereótipos historicamente disseminados.

\section{Referências}

ARAÚJO, Joel Zito. A força de um desejo - a persistência da branquitude como padrão estético audiovisual. Revista USP, São Paulo, n. 69, p.72- 79, mar/maio 2006. Disponível em: <http://www.revistas.usp.br/revusp/article/view/13514>. Acesso em: 10 set. 2017. 


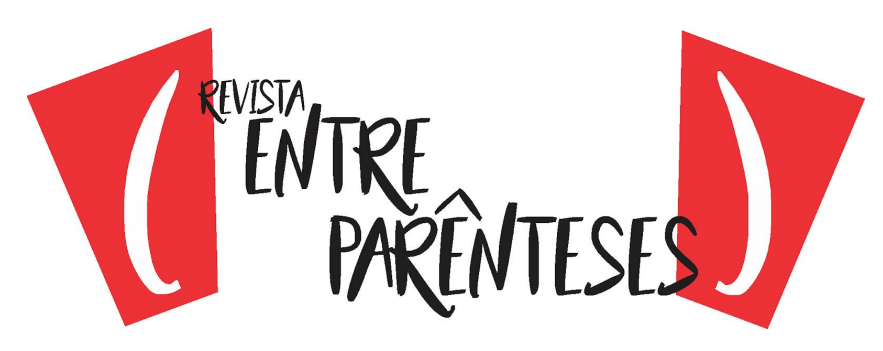

BOURDIEU, Pierre. Poder simbólico.Tradução de Fernandes Tomaz. 11. ed. Rio de Janeiro: Bertrand Brasil, 2007.

CAMARGOS, Roberto. Rap e política: percepções da vida social brasileira. São Paulo: Boitempo, 2015.

CANCLINI, Néstor García. Diferentes, desiguais e desconectados.Tradução Luiz Sérgio Henriques. Rio de Janeiro: UERJ, 2009.

CASHMORE, Ellis. Dicionário de relações étnicas e raciais. 2. ed. São Paulo: Selo Negro, 2000.

FERNANDES, Florestan. A integração do negro na sociedade de classes. 8.ed. São Paulo: Cia. Editora Nacional, 1965.

FERNANDES, Joseli Aparecida. Através do meu canto o morro tem voz: o discurso de resistência no rap de Flávio Renegado. 2018. 132f. Dissertação (Mestrado) - Universidade Vale do Rio Verde, Três Corações, 2018. Disponível em: <http://www.unincor.br/images/imagens/2018/mestrado_letras/dissertacao_joseli.pdf >. Acesso em: 27 abr. 2018.

GIDDENS, Anthony. Modernidade e Identidade. Rio de Janeiro:Zahar, 2002.

GUIMARÃES, Maria Eduarda Araujo. Do Samba ao rap: a música negra no Brasil. Tese (Doutorado). Unicamp, Campinas, 1998. Disponível em: <http://repositorio.unicamp.br/jspui/handle/REPOSIP/281318>. Acesso em: 10 jan. 2017.

HALL, Stuart. A identidade cultural na pós-modernidade. Tradução Tomas Tadeu da Silva e Guaracira Lopes Louro. 11. ed. Rio de Janeiro: DP\&A, 2006.

HOLLANDA, Heloísa Buarque. O engajamento hip hop. In: Cultura como recurso. Salvador: Secretaria de Cultura do Estado da Bahia/Fundação Pedro Calmon, 2012b, p. 25-39. Disponível em: <http://www.heloisabuarquedehollanda.com.br/wp-content/uploads/2013/10/vol_5_ho landa.pdf>. Acesso em: 02 out. 2016.

MUNANGA, Kabengele. Algumas considerações sobre "raça", ação afirmativa e identidade negra no Brasil fundamentos antropológicos. Revista USP, São Paulo, n. 68, p. 46-57, dez./jan. 2006. Disponível em: <http://www.revistas.usp.br/revusp/article/view/13482/15300>. Acesso em: 10 set. 2016. 


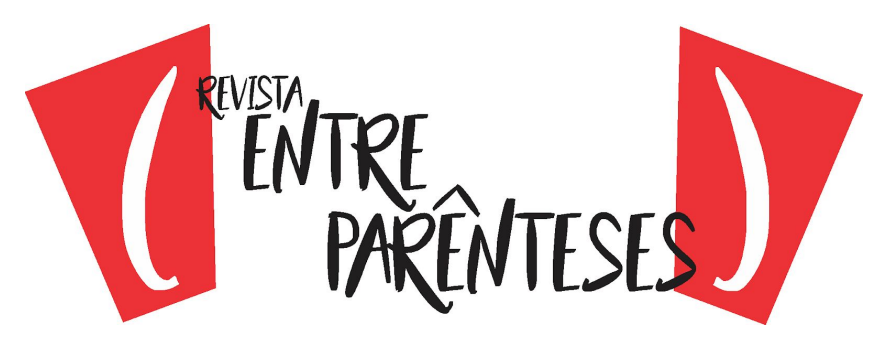

RIGHI, José Volnei. Rap: Ritmo e Poesia Construção identitária do negro no imaginário do RAP brasileiro. 2011. 515f. Tese (Doutorado) - Universidade de Brasília, Brasília, 2011. Disponível em: <http://repositorio.unb.br/handle/10482/10853>. Acesso em: 10 abr. 2016.

RODRIGUES, Elaine de Souza Pinto. "Não tem como segurar essa ventania": Afirmação da Identidade Negra em Filhas do Vento, de Joel Zito Araújo. 2018. 136f. Dissertação (Mestrado) - Universidade Vale do Rio Verde, Três Corações, 2018. Disponível em: <http:// http://www.unincor.br/images/imagens/2018/mestrado_letras/dissertacao_elaine.pdf> Acesso em: 26 abr. 2018.

SILVA, José Carlos Gomes da. Arte e Educação: A experiência do Movimento Hip Hop Paulistano. In: ANDRADE, Elaine Nunes de (Org.). Rap e educação Rap é educação. São Paulo: Summus, 1999, p. 55-63.

SILVA, Marcos Rodrigues. O negro no Brasil: histórias e desafios. São Paulo: FTD S.A, 1987.

SOUZA, Marina de Mello. África e Brasil africano.São Paulo: Ática, 2014.

TELLA, Marco Aurélio Paz. Rap, memória e identidade. In: ANDRADE, Elaine Nunes de (Org.). Rap e educação Rap é educação. São Paulo: Summus, 1999. p. 55-63.

Recebido em: 30/04/2018

Aceito em: 24/09/2018 